\title{
Taking control
}

Citation for published version (APA):

Houben, K., Dassen, F., \& Jansen, A. (2016). Taking control: Working memory training in overweight individuals increases self-regulation of food intake. Appetite, 105, 567-574. https://doi.org/10.1016/j.appet.2016.06.029

Document status and date:

Published: 01/10/2016

DOI:

10.1016/j.appet.2016.06.029

Document Version:

Accepted author manuscript (Peer reviewed / editorial board version)

Document license:

CC BY-NC-ND

\section{Please check the document version of this publication:}

- A submitted manuscript is the version of the article upon submission and before peer-review. There can be important differences between the submitted version and the official published version of record.

People interested in the research are advised to contact the author for the final version of the publication, or visit the DOI to the publisher's website.

- The final author version and the galley proof are versions of the publication after peer review.

- The final published version features the final layout of the paper including the volume, issue and page numbers.

Link to publication

\footnotetext{
General rights Owners
rights.

- You may freely distribute the URL identifying the publication in the public portal. please follow below link for the End User Agreement:

www.umlib.nl/taverne-license

Take down policy

If you believe that this document breaches copyright please contact us at:

repository@maastrichtuniversity.nl

providing details and we will investigate your claim.
}

Copyright and moral rights for the publications made accessible in the public portal are retained by the authors and/or other copyright owners and it is a condition of accessing publications that users recognise and abide by the legal requirements associated with these

- Users may download and print one copy of any publication from the public portal for the purpose of private study or research.

- You may not further distribute the material or use it for any profit-making activity or commercial gain

If the publication is distributed under the terms of Article $25 \mathrm{fa}$ of the Dutch Copyright Act, indicated by the "Taverne" license above, 
This work is licensed under the Creative Commons Attribution-NonCommercial-NoDerivatives 4.0 International License. To view a copy of this license, visit http://creativecommons.org/licenses/by-nc-nd/4.0/

1 RUNNING HEAD: WM training in overweight individuals

2

3

4

5 Taking control: Working memory training in overweight individuals increases self-

6

7

8

9

10

11

12

13

14

15

16

17

18

19 Correspondence may be sent to: Katrijn Houben, Department of Clinical Psychological

20 Science, Faculty of Psychology and Neuroscience, Maastricht University, P.O. BOX

21616,6200 MD M aastricht, The Netherlands. Email:

22

K.Houben@maastrichtuniversity.nl, Phone: +31433881953 regulation of food intake

Katrijn Houben, Fania Dassen, \& Anita Jansen

Department of Clinical Psychological Science

Faculty of Psychology and Neuroscience; M aastricht University

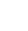


25 Working memory (WM) plays a critical role in cognitive control by shielding self-

26 regulatory goals from distraction by desire-related thoughts and emotions. This study

27 examined whether training WM increases self-regulation in overweight participants.

28 It was hypothesized that WM training would decrease psychopathological eating-

29 related thoughts, (over)consumption of food in response to emotions and external

30 cues, food intake and body weight. Overweight participants $(n=50)$ performed $20-25$

31 sessions of WM training or control/sham training. The dependent measures were self-

32 reported eating-related psychopathology, self-reported emotional/external eating

33 behavior, food intake during a bogus taste test, and body weight, assessed before

34 training, immediately following training, and at one-month follow-up. Relative to

35 control, WM training reduced psychopathological eating-related thoughts and emotional eating (but not external eating). These effects were still present at followup, one month later. Food intake and body weight did not show an overall effect of training, though WM training did reduce food intake among highly restrained participants. WM training effectively reduced eating-related thoughts, overeating in response to negative emotions, and food intake among participants with strong dietary restraint goals. Hence, these findings indicate that WM training may strengthen self-regulation by shielding dieting goals from distraction by unwanted eating-related thoughts and emotions.

\section{Keywords: Obesity; Working Memory; Training}


In the last three decades, the prevalence of obesity has nearly doubled (Finucane et al., 2011; Flegal, 2005; Wang \& Beydoun, 2007), placing more and more individuals at risk of developing cardiovascular diseases, diabetes, musculoskeletal disorders and

51 cancer (World Health Organization, 2009). In 2010, overweight and obesity were estimated to cause 3,4 million deaths worldwide (Lim et al., 2012). Research further shows that, unabated, the increase in obesity will lead to dramatic falls in future life expectancy (Olshansky et al., 2005). A key contributor to the rapid weight gain that

55

occurred over the past 30 years is our obesogenic environment, which encourages

over-consumption of widely-available, inexpensive, energy-dense food and

discourages expenditure of energy though physical activity (Hill, Wyatt, Reed, \& Peters, 2003). The solution to the obesity problem therefore may lie in identifying feasible ways to cope with the current food-rich environment and adhere to the simple principles of the energy balance equation.

One strategy to reduce over-consumption could be to strengthen cognitive control of consumption and body weight. Cognitive control (or executive functioning) is an umbrella term that refers to three basic cognitive functions that allow for goaldirected action amid the endless possibilities afforded to us in real-life situations (Miyake et al., 2000): M aintaining and updating relevant information ('updating'), inhibition of prepotent impulses ('inhibition'), and mental set shifting (task-switching). According to contemporary dual-process models, overconsumption of palatable, energy-dense foods is the result of unintentional, fast-acting impulses that are not or insufficiently regulated via top-down cognitive control (Hofmann, Friese, \& Strack, 2009; Strack \& Deutsch, 2004): Individuals with both strong behavioral impulses to 
71 consume palatable food and low levels of cognitive control are particularly

72 susceptible to over-consumption (Friese, Hofmann, \& Wänke , 2008; Hofmann \&

73 Friese, 2008; Hofmann, Friese, \& Roefs, 2009; Hofmann, Gschwender, Friese, Wiers, \&

74 Schmitt, 2008; Hofmann, Rauch, \& Gawronski, 2007) and weight gain (Nederkoorn,

75 Houben, Hofmann, Roefs, \& Jansen, 2010) compared to individuals with effective

76 cognitive control. Hence, individual differences in cognitive control may explain why

77 some people do not succeed in resisting the lure of palatable, energy-dense foods

78 and achieving a healthy weight.

It has been argued that working memory (WM) may very well lie at the heart

80 of successful cognitive control (Engle et al., 1999; Kane et al., 2001). WM is closely

81 connected to the construct of 'updating' and refers to the ability to maintain an active

82

83

84

85

86

87

88

89

90

91

92

93 mental representation of (self-regulatory) goals, and shield those goals from

distraction (Engle, Tuholski, Laughlin, \& Conway, 1999; Kane, Bleckley, Conway, \&

Engle, 2001; Hofmann, Schmeichel, \& Baddeley, 2012). M oreover, this ability to focus

on goal-relevant information should also relate to people's ability to regulate their

own thoughts and emotions (Hofmann et al., 2012). Indeed, increased WM capacity is

related to less thought intrusions and mind-wandering (Brewin \& Beaton, 2002;

Brewin \& Smart, 2005; Kane et al., 2007) and better emotion-regulation (Schmeichel

\& Demaree, 2010; Schmeichel, Volokhov, \& Demaree, 2008). Importantly, overweight and obesity have been associated with reduced cognitive control, including WM (Smith, Hay, Campbell, \& Trollor, 2011), which begs the question whether training cognitive control, and WM in particular, may translate into better behavioral selfregulation in overweight and obese individuals. 
Previous studies showed that WM can be improved via adaptive training and

\section{Participants}

112 Participants were recruited via advertisements in local newspapers about the

113 possibility to participate in research exploring WM training as an intervention for that such training is effective in reducing clinical symptoms (for reviews see Klingberg 2010; Morrison \& Chein, 2011). It is important to note, however, that there has also been criticism on the effectiveness of WM training claiming that there is yet insufficient evidence of its efficacy. Specifically, it has been argued that more scientific evidence is needed to support both near transfer of WM training to untrained WM tasks, and far transfer to WM-related abilities and behavior (e.g., Shipstead, Redick, \& Engle, 2012). In the present study, it was examined whether WM training decreases over-consumption and body weight in a sample of overweight participants. Participants either performed WM training or control tasks (sham training) for 25 days. It was expected that WM training would increase self-regulation and cognitive control as evidenced by (1) reduced pathological eating-related thinking, (2) decreased (over-)consumption of food in response to emotions and external cues, (3) reduced consumption of palatable, energy-dense foods, and (4) a decrease in body weight.

\section{Materials and Methods}

overweight. The advertisements specifically asked for individuals who had overweight and who were motivated to lose weight. Eligibility required that participants were aged 18 to 65, and had a Body Mass Index (BMI) higher than 25 (i.e., A BMI above 25 indicates overweight). Of the 67 participants who responded to the advertisements 
118 and met the eligibility criteria, 62 participants completed the pretest. Twelve

119 participants dropped out after missing too many training sessions ${ }^{1}$. The remaining 50

120 (37 female) participants completed at least 20 training sessions, the pretest, posttest

121 and follow-up. Of the final sample, $6 \%$ received primary education, $66 \%$ received

122 secondary education, and $28 \%$ received higher education. See also Table 1 for

123 participant characteristics. The study was approved by the Ethical Review Committee

124 Psychology and Neuroscience.

125

126 Materials \& Measures

127 Working memory training. The WM training (Houben, Wiers, \& Jansen, 2011;

128 Klingberg, Forssberg, \& Westerberg, 2002) consisted of three tasks: A visuospatial

129 WM task, a backward digit span task, and a letter span task (presented in this order).

130 During the visuospatial WM task, a sequence of squares in a $4 \times 4$ grid changed in color

131 on the computer screen. Participants had to reproduce this sequence by clicking the

132 squares that had changed color in the correct order using the computer mouse.

133 During the backward digit span, a sequence of numbers was presented on the

134 computer screen, which participants had to reproduce in reversed order, using either

135 the computer mouse or the keyboard. In the letter span task, a sequence of letters

136 was presented on the computer screen in a circle. One of the positions in this circle

137 was then indicated and participants had to reproduce the corresponding letter using

138 the keyboard. All three tasks consisted of 30 trials (one block).

139 In the training condition, the difficulty level of all three WM tasks was

140 automatically adjusted on a trial-by-trial basis (cf. Houben et al., 2011; Klingberg et

141 al., 2002): Each task initially started with a sequence of three items. When 
142 participants correctly reproduced this sequence two times in a row, one item was

143 added to the sequence on the next trial. When participants could not correctly

144 reproduce the sequence on two consecutive trials, the sequence in the next trial was

145 reduced by one item. In the control condition, the difficulty level of the WM tasks

146 remained on the initial easy level (three items in a sequence; cf. Houben et al., 2011;

147 Klingberg et al., 2002). Before and after training, WM was measured using the same

148 three tasks, but these assessment tasks ended when participants were unable to

149 reproduce a sequence on two consecutive trials. The outcome measure for each WM

150 task was the amount of items in the sequence that could be correctly reproduced.

151 These three scores were averaged to calculate a total WM score.

152

Eating Disorder Examination Questionnaire (EDE-Q). The EDE-Q (Fairburn \&

154 Beglin, 1994; Fairburn \& Cooper, 1993) is a 36-item self-report measure of eating

155 disorder psychopathology. The EDE-Q contains 23 items assessing eating disorder

156 psychopathology over the previous 28 days. These items are answered on a 7-point

157 Likert scale ( $0=$ 'not one day'; $6=$ 'every day'). The 23 items together comprise one

158 global score (Cronbach's $\alpha=.90$ ) as well as four subscales: Restrained eating

159 (Cronbach's $\alpha=.73$ ), preoccupation with food (Cronbach's $\alpha=.67)$, weight concern

160 (Cronbach's $\alpha=.78$ ) and body shape concern (Cronbach's $\alpha=.88$ ). Higher scores

161 indicate stronger eating disorder psychopathology.

162

Dutch Eating Behaviour Questionnaire (DEBQ). The DEBQ (Van Strien, 2005;

164 Van Strien, Frijters, Bergers, \& Defares, 1986) is a 33-item self-report measure of

165 emotional eating (Cronbach's $\alpha=.96)$, external eating (Cronbach's $\alpha=.77$ ) and 
166 restrained eating (Cronbach's $\alpha=.90$ ). All items are scored on a 5-point Likert scale (1

$167=$ 'Never'; 5 ='Very often'). Item examples: 'Do you have a desire to eat when you are

168 irritated?' (emotional eating), 'If foods smells and looks good, do you eat more than

169 usual?' (external eating) and 'Do you try to eat less at mealtimes than you would like

170 to eat?' (dietary restraint). M eans are calculated for the three subscales with higher

171 scores indicating increased emotional, external or dietary restraint.

172

Bogus taste test. Food consumption was measured using a bogus taste test.

174 Participants were presented with four bowls containing different palatable energy-

175 dense foods: salted potato chips (541 kcal/100gr), chocolate cookies ( $465 \mathrm{kcal} / 100$

$176 \mathrm{gr})$, milk chocolate (530 kcal/ $100 \mathrm{gr})$, coated peanuts ( $535 \mathrm{kcal} / 100 \mathrm{gr})$. Participants

177 were told that we were interested in their taste perception of a number of food

178 products. Participants were instructed that they were allowed to consume as much or

179 as little of the food as they wished while completing food ratings: Participants first

180 indicated how much they experienced hunger and desire to eat the food on a $100 \mathrm{~mm}$

181 Visual Analogue Scale ( $0=$ 'no desire/not hungry'; $100=$ 'strong desire/ very hungry').

182 Next, they compared and rated the different food products on a number of taste

183 dimensions. After 15 minutes, the experimenter removed the bowls of food and the

184 amount of food consumed was measured outside the test room. Total amount of

185 calories was calculated as an index of food intake.

186

Dietary restraint. Dietary restraint was measured using the revised Restraint

188 Scale (RS; Herman \& Polivy, 1980). The RS is a self-report questionnaire consisting of

18910 items that measure dieting concern/intentions and weight fluctuations 
190 (Cronbach's $\alpha=.70$ ). Higher scores indicate an increased intention to restrict food

191 intake.

192

194 calculate participants' Body Mass Index (kg/m²; BMI).

195

\section{Procedure}

197 After giving consent, participants performed the bogus taste test and the assessment

198 WM tasks. Next, they filled out the Restraint Scale, EDE-Q and DEBQ, and their weight

199 and height were measured. Participants were then randomly assigned to the training

200 or control condition and were informed that they would perform a WM training

201 consisting of 25 sessions via the Internet (so they did not have to come to the lab for

202 the training sessions; participants were sent invitations for each training session via

203 email together with a personalized link to start the session). Participants were given

204 two days to complete a training session. Each session lasted about 30 minutes in

205 total. If participants did not complete a session in time, that session was marked as

206 missed, and participants moved on to the next session. In total, participants could

207 miss up to 5 training sessions. Hence, the total number of training sessions varied

208 between 20 and $25(M=23.02, S D=1.80$; the training sessions were on average

209 completed within 33.92 days, $S D=8.23$, range: $25-66)^{2}$. Upon completing the

210 training, the posttest session was scheduled in the lab (on average 9.52 days, SD =

2116.19 , after the last training session). At posttest, participants again performed the

212 bogus taste test and the WM assessment, they filled out the EDE-Q and DEBQ, and

213 their weight was measured. The follow-up session was scheduled one month after the 
214 posttest and included the same measures. Upon completing the experiment,

215 participants received a gift certificate of $50 €$ as remuneration for their participation.

217 Design \& statistical analyses

218 Participants were randomly allocated to one of two groups: Active working memory

219 training $(n=24)$ or control training $(n=26)$. Randomization checks showed no

220 significant differences between conditions for any potential confounding factors

221 (Table 1). Data were analyzed using mixed-effects ANOVA with condition as between-

222 subjects factor (training versus control) and time as within-subjects factor (pretest,

223 posttest and follow-up) $)^{3}$.

224

225

226

227

228

229

230 the course of the training period (see Figure 1). In the training condition, in contrast,

231 the training was adjusted adaptively to participants' performance. As can be seen in

232 Figure 1, participants in the training condition showed a steady increase in working

233 memory performance during the training period.

\section{Working memory}

236 A mixed ANOVA on WM task performance showed significant main effects of time,

\section{Results}

\section{Manipulation Check}

In the control condition, the difficulty of the training tasks always remained on the easiest level with only three to-be-remembered items in each task. Consequently, the performance of participants in the control condition remained at the same level over $F(2,96)=67.31, p<.001, \eta^{2}=.58$, and condition, $F(1,48)=7.19, p=.01, \eta^{2} p=.13$, as 
238 well as a significant time* condition interaction, $F(2,96)=17.29, p<.001, \eta_{p}^{2}=.27$

239 (see Figure 2). Follow-up analyses per condition showed a significant increase over

240 time in WM performance in both the control condition, $F(2,50)=17.86, p<001, \eta^{2} p$

$241=.42$, and the training condition, $F(2,46)=57.14, p<.001, \eta^{2} p=.71$. Contrasts

242 indicated that, in both the training and control condition, the increase in WM

243 performance from pretest to posttest was significant, $F(1,23)=98.68, p<.001, \eta^{2}{ }_{p}=$

244.81 , and $F(1,25)=28.20, p<001, \eta_{p}^{2}=.53$, respectively, with a larger increase in the

245 training condition than in the control condition, $F(1,48)=6.13 p=.02, \eta^{2}=.11$. In

246 addition, both conditions also improved in WM performance from pretest to follow-

up, $F(1,23)=66.63, p<.001, \eta_{p}^{2}=.74$, and $F(1,25)=6.36, p=.02, \eta^{2} p=.20$,

248 respectively. At follow-up, WM performance of the training condition was still

249 significantly higher compared to control, $F(1,48)=23.38, p<.001, \eta_{p}^{2}=.33$.

\section{$251 \quad$ Eating Psychopathology}

252 For the EDE-Q, separate analyses were performed for the global EDE-Q score, and for

253 the four separate subscales: Eating concern, shape concern, weight concern, and

254 dietary restraint. For eating concern, results showed a significant main effect of time,

$255 F(2,96)=9.54, p<.001, \eta_{p}^{2}=.17$ (but no effect of condition, $F(1,48)=.14, p=.71, \eta_{p}^{2}$

$256<.01)$, and a significant time* condition interaction, $F(2,96)=3.08, p=.05, \eta^{2} p=.06$.

257 Follow-up analyses indicated a significant decrease in eating concern over time in the

258 training condition, $\mathrm{F}(2,46)=7.47, \mathrm{p}<.01, \eta_{\mathrm{p}}^{2}=.25$, but not in the control condition,

$259 F(2,50)=2.47, p=.10, \eta^{2}=.10$ (see Table 2). Contrasts confirmed a significant

260 decrease in the training condition from pretest to posttest, $F(1,23)=16.26, p<.01$, 
$261 \eta_{p}^{2}=.41$, that was still significant at one month follow-up, $F(1,23)=4.27, p=.05, \eta_{p}^{2}=$

262

263

264

265

266

267

268

269

270

271

272

273

274

275

276

277

278

279

280

281

282

283

284

.16

Similarly, analyses for the shape concern subscale also showed a significant time effect, $F(1.77,84.88)=10.59, p<.001, \eta_{p}^{2}=.18$ (but not of condition, $F(1,48)=$ $.52, p=.48, \eta_{p}^{2}=.01$ ) that was qualified by a significant time* condition interaction, $\mathrm{F}(1.77,84.88)=5.17, p=.01, \eta^{2} p=.10(\text { see Table } 2)^{4}$. Follow-up analyses indicated a significant decrease in shape concern following training, $F(2,46)=12.68, p<.001, \eta^{2} p$ $=.36$, indicating a significant decrease in shape concern from pretest to posttest, $F(1,23)=19.81, p<.001, \eta_{p}^{2}=.46$, and to follow-up, $F(1,23)=12.47, p<.01, \eta_{p}^{2}=.35$. In the control condition, there was no significant change in shape concern over time, $F(2,50)=.65, p=.53, \eta_{p}^{2}=.03$

A similar pattern emerged for the weight concern subscale of the EDE-Q (see Table 2), but here the interaction between time and condition did not reach significance, $F(2,96)=2.02, p=.14, \eta^{2} p=.04$. There was a significant effect of time, $F(2,96)=5.56, p<.01, \eta_{p}^{2}=.10$, indicating an overall decrease in weight concern. The main effect of condition was not significant, $F(1,48)=.14, p=.71, \eta^{2}<.01$. For the dietary restraint subscale of the EDE-Q, no effects reached significance (time: $F(1.65$, 79.26) $=2.10, p=.13, \eta_{p}^{2}=.04$; condition: $F(1,48)=.40, p=.53, \eta_{p}^{2}=.01$; time* condition: $\left.F(1.65,79.26)=.73, p=.48, \eta^{2} p=.02\right)^{4}$.

This pattern of results was also illustrated in the analysis of the total EDE-Q score: In addition to a significant main effect of time, $F(1.71,82.25)=14.34, p<.001$, $\eta_{p}^{2}=.23$ (no significant effect of condition, $F(1,48)=.26, p=.61, \eta_{p}^{2}=.01$ ), the time* condition interaction was significant, $F(1.71,82.25)=3.99, p=.02, \eta^{2} p=.08$ (see Table 2$)^{4}$, indicating an overall decrease in EDE-Q scores over time in the training 
285 condition, $F(1.50,34.42)=16.71, p<.001, \eta_{p}^{2}=.42$, that was significant at posttest, $286 \mathrm{~F}(1,23)=23.88, \mathrm{p}<.001, \eta^{2} \mathrm{p}=.51$, as well as at follow-up one month later, $F(1,23)=$ $28715.53, p<.01, \eta_{p}^{2}=.40$. No effect of time emerged in the control condition, $F(2,50)=$ $2.13, p=.13, \eta^{2} p=.08$.

\section{Emotional and external eating}

291 Separate analyses were performed for the three subscales of the DEBQ: emotional eating, external eating and dietary restraint. For emotional eating ${ }^{4}$, the significant main effect of time, $F(1.73,83.19)=3.60, p=.04, \eta_{p}^{2}=.07$, was qualified by a significant time* condition interaction, $F(1.73,83.19)=3.63, p=.04, \eta^{2}{ }_{p}=.07$ (see Table 2). The main effect of condition was not significant, $F(1,48)<.01, p=.97, \eta_{p}^{2}<$ .01. Follow-up analyses per condition showed a significant decrease in emotional eating over time in the training condition, $F(2,46)=5.87, p<.01, \eta^{2} p=.20$, but no

298 effect of time in the control condition, $F(2,50)=.81, p=.45, \eta^{2} p=.03$. Contrasts confirmed that in the training condition, emotional eating was significantly reduced at posttest, $F(1,23)=9.35, p<.01, \eta_{p}^{2}=.29$, and at follow-up, $F(1,23)=7.37, p=.01, \eta_{p}^{2}$

$301=.24$, compared to pretest. For external eating only the main effect of time reached significance, $F(2,96)=7.86, p<.01, \eta_{p}^{2}=.14$, indicating a decrease in external eating

303 across both conditions (condition: $F(1,48)=.01, p=.93, \eta_{p}^{2}<.01$; time*condition: $\left.F(2,96)=.27, p=.77, \eta_{p}^{2}=.01\right)$. For dietary restraint there were no significant effects 305 (time, $F(1.70,81.43)=2.63, p=.09, \eta_{p}^{2}=.05$; condition, $F(1,48)=.02, p=.89, \eta_{p}^{2}<$ 306.01 ; time* condition, $\left.F(1.70,81.43)=.66, p=.49, \eta_{p}^{2}=.01\right)^{4}$. 
310 Results showed no differences between the training and control condition with

311 respect to hunger (condition: $F(1,48)=.04, p=.84, \eta_{p}^{2}=.00$; time: $F(2,96)=1.42, p=$

$312.25, \eta_{p}^{2}=.03$; condition*time: $\left.F(2,96)=.74, p=.48, \eta^{2} p=.02\right)$ or craving (condition:

$313 \mathrm{~F}(1,48)=.01, p=.91, \eta^{2} \mathrm{p}=.00$; time: $\mathrm{F}(2,96)=61, p=.54, \eta^{2} \mathrm{p}=.01$; condition*time:

$\left.314 F(2,96)=1.06, p=.35, \eta_{p}^{2}=.02\right)$. Food intake during the bogus taste test showed no

315 significant time* condition interaction, $F(1.62,77.52)=.38, p=.64, \eta^{2} p=.01$, nor

316 significant main effects (time, $F(1.62,77.52)=2.04, p=.15, \eta^{2} p=.04$; condition,

$\left.317 \mathrm{~F}(1,48)=.13, \mathrm{p}=.72, \eta_{\mathrm{p}}^{2}<.01\right)^{4}$.

It is important to note here that research in other areas of cognitive control

training (i.e., inhibitory control training) indicates a moderating role of dietary restraint on training effects with larger effects on food intake in participants with high levels of dietary restraint (e.g., Houben \& Jansen, 2011; see also Jones et al., 2016).

Theoretically, stronger cognitive control should result in greater concordance between one's current goals and behavior (Hofmann et al., 2009). Hence, it is unlikely that increasing cognitive control will lead to behavior change when there is no concurrent dieting goal present. Similarly, WM is critical for sustained attention to one's goals (Engle et al., 1999; Kane et al., 2001; Hofmann et al., 2012). Training WM should therefore translate into lower food intake especially for participants with strong dieting goals but not for participants without active dieting goals.

We therefore also a post-hoc analysis to examine the effect of baseline dietary restraint (measured with the RS), condition and their interaction on food intake at pretest, posttest and at follow-up. Restraint scores were z-standardized and entered as a continuous predictor in the ANOVA (Aiken \& West, 1991). One influential outlier 
333 (Cook's $>1.5$ ) was excluded from the analyses. For food intake at pretest, none of the

334 effects reached significance (restraint: $F(1,45)=.48, p=.49, \eta^{2} p=.01$; condition:

$335 F(1,45)=2.58, p=.12, \eta_{p}^{2}=.05$; condition*restraint: $\left.F(1,45)=.23, p=.63, \eta^{2} p=.01\right)$.

336 At posttest, the expected interaction between dietary restraint and condition was

337 significant, $F(1,45)=3.91, p=.05, \eta_{p}^{2}=.08$. The main effects of restraint and

338 condition did not reach statistical significance (restraint: $F(1,45)=.04, p=.83, \eta_{p}^{2}<$

339.01 ; condition: $\left.F(1,45)=.28, p=.60, \eta^{2}{ }_{p}=.01\right)$. We analyzed the effect of training

340 separately for participants scoring high and low on the RS (respectively 1 SD above

341 and 1 SD below the mean score; Cohen, Cohen, West, \& Aiken, 2003). For participants

342 with lower dietary restraint (-1 SD), there was no significant difference between

343 training and control with respect to food intake, $F(1,45)=1.26, p=.27, \eta_{p}^{2}=.03$, but

344 among high restrained participants ( $+1 \mathrm{SD})$, food intake was reduced in the training

345 condition compared to control, $F(1,45)=3.49, p=.07, \eta^{2} p=.07$ (see Figure 3).

346 Consumption at follow-up showed a similar pattern of results, though the interaction

347 between dietary restraint and condition was not significant, $F(1,45)=2.11, p=.15, \eta^{2} p$

$348=.05$ (restraint: $F(1,45)=.43, p=.52, \eta_{p}^{2}=.01$; condition: $F(1,45)=.61, p=.44, \eta_{p}^{2}=$ $349.01)$

\section{BMI}

352 None of the effects of time or condition were significant for BMI (time: $F(1.50,71.87$ )

$353=1.00, p=.35, \eta_{p}^{2}=.02$; condition: $F(1,48)=.11, p=.74, \eta_{p}^{2}<.01$; time* condition:

$\left.354 \mathrm{~F}(1.50,71.87)=.09, \mathrm{p}=.86, \eta_{\mathrm{p}}^{2}<.01\right)^{4}$, indicating no significant change in body 355 weight over time. 
358 Given the prominent role of cognitive control in self-regulatory behavior like food

359 intake, the aim of the present study was to examine whether boosting WM via

360 training would lead to better self-regulation in overweight individuals. As expected,

361 participants who received WM training, relative to participants in the control

362 condition, reported overall less eating-related concerns (especially less concern about

363 eating and shape), and less emotional eating (but not external eating), immediately

364 following training and at one-month follow-up. Food intake and body weight did not

365 show an overall effect of training. Results, however, did show the expected effect of

366 WM training on food intake in highly restrained participants, indicating that WM

367 training increased correspondence between dietary goals and food intake.

368 WM supports self-regulation by enabling individuals to resist the attentional

369 capture of tempting stimuli at early stages of information processing, thereby

370 shielding self-regulatory goals from competing goals and distraction (Kane et al.,

$3712001 ;$ Hofmann et al., 2012). As such, WM relates to the ability to regulate one's own

372 thoughts and emotions, by focusing attention on goal-relevant information and

373 ignoring irrelevant, distracting information (Hofmann et al., 2012). In line with this

374 idea, WM training reduced pathological ruminative thoughts about food, weight, and

375 body shape. This finding fits with previous research showing an association between

376 preoccupying cognitions and WM impairment in dieters: Preoccupying thoughts

377 about food, weight and body shape seem to consume WM resources with

378 detrimental effects on WM performance (Green, Elliman, \& Rogers, 1997; Kemps \&

379 Tiggemann, 2005; Kemps, Tiggemann, \& M arshall, 2005; Vreugdenburg, Bryan, \&

380 Kemps, 2003). The present results add to these findings by demonstrating that WM 
381 training alleviates distraction by preoccupying cognitions related to dieting, weight, 382 food, and body shape.

383 Further, WM training decreased self-reported emotional eating indicating that 384 participants who received WM training were better able to regulate their emotions in 385 other ways than by (over)eating compared to participants in the control condition.

386 This finding is consistent with previous studies showing that individuals with higher

387 WM capacity, as opposed to individuals with lower levels of WM, are better able to 388 regulate emotions and appraise emotional stimuli in an unemotional manner

389 (Schmeichel \& Demaree, 2010; Schmeichel, Volokhov, \& Demaree, 2008). It was also 390 expected that WM training would increase the resilience to temptation by food cues.

391 Unexpectedly, self-reported external eating was reduced over time in both conditions. Previous research, however, has indicated that the external eating 393 subscale of the DEB-Q (but not the emotional eating subscale or the dietary restraint 394 subscale) is affected by visceral states and may thus be a state rather than a trait 395 measure (Evers et al., 2011). It is possible that such fluctuations in visceral states over 396 time have caused this slight, albeit significant, decrease in external eating across 397 conditions. These findings thus indicate that WM training might help overweight and 399 obese individuals to create a more healthy style of thinking about their body and 400 eating behavior. Nevertheless, the present findings did not show the expected effects 401 of WM training on body weight, and effects on food intake were only found among 402 highly restrained eaters. Specifically, highly restrained eaters who received WM 403 training showed a reduction in food intake relative to participants in the control 404 condition. Perhaps this finding is not surprising given that high WM capacity increases 
405 the correspondence between dieting goals and eating behavior (Hofmann et al., 406 2007). Without (dieting) motivation, it is unlikely that cognitive control training will 407 lead to behavioral change. Thus, the strongest effects on food intake are to be 408 expected for participants who hold strong dietary restraint standards. It is interesting 409 to note that training studies which have targeted a different cognitive control ability, 410 namely response inhibition, have also shown stronger effects of inhibition training on 411 food intake among highly restrained eaters (Houben \& Jansen, 2011; Veling, Aarts, \& 412 Papies, 2011; see also Jones et al., 2016), indicating that cognitive control training 413 may indeed be more effective for participants with high levels of dietary restraint. While WM training did not influence body weight in the present study, it

415 should be noted that inhibition training has been shown to reduce both food intake 416 (e.g., Houben \& Jansen, 2011; 2015; Veling et al., 2011; Lawrence, Verbruggen, 417 Morrison, Adams, \& Chambers, 2015; Veling, Aarts, \& Stroebe, 2013) and body weight 418 (e.g., Lawrence et al., 2015; Veling, van Koningsbruggen, Aarts, \& Stroebe, 2014). As 419 such, inhibition training effects appear to be stronger and more robust compared to 420 effects of WM training. Perhaps this is due to differences in terms of the behavioral421 specificity of the training. Inhibition training has been shown to be effective only 422 when the training is focused on strengthening inhibition over food-related responses, 423 but not when general response inhibition is targeted during training (Allom, Mullan, \& 424 Hagger, 2016). It might therefore be interesting for future research to contrast the present findings for general WM training with more applied, diet-relevant WM 426 training.

A limitation to the present findings is that we did not measure dieting 428 motivations, and as explained above, it is unlikely that WM training will translate into 
429 weight loss when participants are unmotivated to lose weight. Future research should

430 therefore screen participants for dieting motivations and test whether WM training

431 might be more effective among overweight participants who are committed to losing

432 weight. A second limitation is that we did not measure beliefs regarding the training

433 in the two conditions. While both conditions received the same instructions, we

434 cannot rule out that participants in the control condition may have become suspicious

435 and did not belief that they were receiving WM training. It is therefore important to

436 include measures of expectancies and beliefs regarding the training and the purpose

437 of the study in future studies to rule out demand artefacts. Another limitation to this

438 study concerns the fact that we did not measure transfer effects of the WM training

439 to other non-trained tasks of executive functions (WM, task-switching, inhibition).

440 Earlier research has shown transfer effects to non-trained tasks (see Klingberg, 2010

441 for a review), though the generalization to non-trained tasks has also raised

442 considerable debate (e.g., Shipstead et al., 2012). Further, it is possible that WM

443 training in isolation is not effective as a weight loss intervention and will only be

444 effective in reducing weight in combination with additional (lifestyle) interventions. In

445 this way, overweight individuals who are highly motivated to diet and who are

446 provided with dieting strategies might profit the most from WM training that boosts

447 self-regulatory abilities. Future research should thus further examine the

448 effectiveness of WM training on weight in combination with other weight loss

449 interventions.

450 In conclusion, WM training successfully reduced emotional eating and

451 psychopathological eating-related concerns in a sample of overweight participants.

452 Moreover, WM training also reduced food intake, but only among highly restrained 
453 eaters, underscoring the need to further examine the effectiveness of WM training in 454 target groups of overweight individuals who are highly motivated to lose weight. 455 
457 1. Of the 12 participants who dropped out, 9 participants were in the training

458 condition and 3 participants were in the control condition. The participants who

459 dropped out did not differ from the participants who finished the study in terms

460 of age, or scores on WM, DEBQ, EDE-Q and RS (all $F<1$ ). Participants who

461 dropped out, however, did have a lower $\mathrm{BMI}(\mathrm{M}=28.84, \mathrm{SD}=2.58, \mathrm{~F}(1,60)=$

$4625.72, p=.02$, compared to the rest of the sample ( $M=31.56, S D=3.72$ ).

463 2. Note that the range normally should have been 25 - 50 days because participants

464 were only allowed to do one session per day and had to complete a session every

465 two days. However, two participants were given some extension to these rules

466 due to personal issues.

467 3. We also performed an Intention To Treat (ITT) analysis on all dependent variables

468 using the "last observation carried forward method" method. In the ITT analyses,

469 all participants were included, rather than including only the participants who

470 completed the study as in the Per Protocol analyses. Including all participants in

471 the ITT analyses did not change any of the effects compared to the Per Protocol

$472 \quad$ analyses.

4734 . Due to violation of the sphericity assumption, degrees of freedom were

$474 \quad$ Greenhouse-Geisser adjusted. 
477 This study was funded by M aastricht University. The authors declare that they have 478 no conflicts of interest.

479 
481 Allom, V., Mullan, B., \& Hagger, M. (2016). Does inhibitory control training improve 482 health behaviour? A meta-analysis. Health Psychology Review, 10, 168-186.

483 Aiken, L. S., \& West, S. G. (1991). Multiple regression: Testing and interpreting $484 \quad$ interactions. Newbury Park: Sage.

485 Borella, E., Carretti, B., Riboldi, F., \& De Beni, R. (2010). Working memory training in older adults: evidence of transfer and maintenance effects. Psychology and Aging $25,767-778$.

Brewin, C. R., \& Beaton, A. (2002). Thought suppression, intelligence, and working memory capacity. Behaviour Research and Therapy, 40, 923-930.

Brewin, C. R., \& Smart, L. (2005). Working memory capacity and suppression of intrusive thoughts. Journal of Behavior Therapy and Experimental Psychiatry, 36, 61-68.

Cohen, J., Cohen, P., West, S. G., \& Aiken, L. S. (2003). Applied multiple regression/ correlation analysis for the behavioral sciences. New Jersey: Lawrence Erlbaum Associates.

496 Engle, R. W., Tuholski, S. W., Laughlin, J.E., \& Conway, A. R. A. (1999). Working memory capacity, short-term memory, and general fluid intelligence: A latentvariable approach. Journal of Experimental Psychology: General, 128, 309-331.

499 Evers, C., Stok, F. M., Danner, U. N., Salmon, S. J., de Ridder, D. T. D., \& Adriaanse, M. A. (2011). The shaping role of hunger on self-reported external eating status. Appetite, 57, 318-320.

502 Fairburn, C. G, \& Beglin, S. J. (1994). The assessment of eating disorders: interview or 503 self-report questionnaire? International Journal of Eating Disorders, 16, 363-370. 
504 Fairburn, C. G., \& Cooper, Z. (1993). The Eating Disorder Examination (twelfth

505 edition). In C. G. Fairburn, \& G. T. Wilson (Eds), Binge Eating: Nature, Assessment

506 and Treatment (pp. 317- 360). New York: Guilford Press.

507 Finucane, M. M., Stevens, G. A., Cowan, M. J., Danaei, G., Lin, J. K., Paciorek, C. J., ...

508 Ezzati, M. (2011). National, regional, and global trends in body-mass index since

509 1980: systematic analysis of health examination surveys and epidemiological

$510 \quad$ studies with 960 country-years and 9. 1 million participants. Lancet, 377, 557-

511567.

512 Flegal, K. M. (2005). Epidemiologic aspects of overweight and obesity in the United

$513 \quad$ States. Physiology \& Behavior, 86, 599-602.

514 Friese, M., Hofmann, W., \& Wänke, M. (2008). When impulses take over. Moderated

515 predictive validity of explicit and implicit attitude measures in predicting food

516 choice and consumption behaviour. British Journal of Social Psychology, 47, 397-

$517 \quad 419$.

518 Green, M. W., Elliman, N. A., \& Rogers, P. J. (1997). Impaired cognitive processing in

519 dieters: Failure of attention focus or resource capacity limitation ? British Journal

$520 \quad$ of Health Psychology, 2, 259-267.

521 Herman, C. P., \& Polivy, J. P. (1980). Restrained eating. In A. J. Stunkard (Ed.), Obesity

522 (pp. 208-225). Philadelphia: Saunders.

523 Hill, J. O., Wyatt, H. R., Reed, G. W., \& Peters, J. C. (2003). Obesity and the

524 environment: where do we go from here? Science, 299, 853-855.

525 Hofmann, W., Friese, M., \& Roefs, A. (2009). Three ways to resist temptation. The

526 independent contributions of executive attention, inhibitory control and affect 
regulation to the impulse control of eating behavior. Journal of Experimental Social Psychology, 45, 431-435.

529 Hofmann, W., Friese, M., \& Strack, F. (2009). Impulse and self-control from a dual-

$530 \quad$ systems perspective. Perspectives on Psychological Science, 4, 162-176.

531 Hofmann, W., \& Friese, M. (2008). mpulses got the better of me. Alcohol moderates 532 the influence of implicit attitudes toward food cues on eating behavior. Journal of $533 \quad$ Abnormal Psychology, 117, 420-427.

534 Hofmann, W., Gschwender, T., Friese, M., Wiers, R. W., \& Schmitt, M. (2008). Working 535 memory capacity and self- regulatory behavior: toward an individual differences perspective on behavior determination by automatic versus controlled processes.

538 Hofmann, W., Rauch, W., \& Gawronski, B. (2007). And deplete us not into temptation.

539 Automatic attitudes, dietary restraint, and self-regulatory resources as

540 determinants of eating behavior. Journal of Experimental Social Psychology, 43, $541 \quad 497-504$.

542 Hofmann, W., Schmeichel, B. J., \& Baddeley, A.D. (2012). Executive functions and self543 regulation. Trends in Cognitive Sciences, 16, 174-180.

544 Houben, K., \& Jansen, A. (2015). Chocolate equals stop: Chocolate-specific inhibition 545 training reduces chocolate intake and go associations with chocolate. Appetite, $546 \quad 87,318-323$.

547 Houben, K., \& Jansen, A. (2011). Training inhibitory control: A recipe for resisting $548 \quad$ sweet temptations. Appetite, 56, 345-349. 
549 Houben, K., Wiers, R. W., \& Jansen, A. (2011). Getting a grip on drinking behavior:

550 Training working memory to reduce alcohol abuse. Psychological Science, 22,

$551968-975$.

552 Jones, A., Di Lemma, L. C. G., Robinson, E., Christiansen, P., Nolan, S., Tudur-Smith, C., $553 \&$ \& Field, M. (2016). Inhibitory control training for appetitive behaviour change: A 554 meta-analytic investigation of mechanisms of action and moderators of 555 effectiveness. Appetite, 97, 16-28.

556 Kane, M. J., Bleckley, M. K., Conway, A. R. A., \& Engle, R. W. (2001). A controlled557 attention view of working-memory capacity. Journal of Experimental Psychology: 558 General, 130, 169-183.

559 Kane, M. J., Brown, L. H., McVay, J. C., Silvia, P. J., Myin-Germeys, .l,\& Kwapil, T. R. 560 (2007). For whom the mind wanders, and when: An experience-sampling study of 561 working memory and executive control in daily life. Psychological Science, 18, $562 \quad 614-621$.

563 Kemps, E., Tiggemann, M., \& Marshall, K. (2005). Relationship between dieting to lose 564 weight and the functioning of the central executive. Appetite, 45, 287-294.

565 Kemps, E., \& Tiggemann, M. (2005). Working memory performance and 566 preoccupying thoughts in female dieters: Evidence for a central executive 567 impairment. British Journal of Clinical Psychology, 44, 357-366.

568 Klingberg, T., Forssberg, H., \& Westerberg, H. (2002). Training of working memory in 569 children with ADHD. Journal of Clinical Experimental Neuropsychology, 24, 781-

571 Klingberg, T. (2010). Training and plasticity of working memory. Trends in Cognitive 572 Sciences, 14, 317-324. 
Lawrence, N. S., O'Sullivan, J., Parslowa, D., Javaid, M., Adams, R. C., Chambers, C. D., Kos, K. \& Verbruggen, F. (2015). Training response inhibition to food is associated with weight loss and reduced energy intake. Appetite, 95, 17-28.

Lawrence, N. S., Verbruggen, F., Morrison, S., Adams, R. C., \& Chambers, C. D. (2015). Stopping to food can reduce intake. Effects of stimulus-specificity and individual differences in dietary restraint. Appetite, 85, 91-103.

Lim, S. S., Vos, T., Flaxman, A. D., Danaei, G., Shibuya, K., Adair-Rohani, H., ... Ezzati, M. (2012). A comparative risk assessment of burden of disease and injury attributable to 67 risk factors and risk factor clusters in 21 regions, 1990-2010: a systematic analysis for the Global Burden of Disease Study 2010. Lancet, 380, 2224-2260.

Miyake, A., Friedman, N. P., Emerson, M. J., Witzki, A. H., Howerter, A., \& Wager T. (2000). The unity and diversity of executive functions and their contributions to complex "frontal lobe" tasks: A latent variable analysis. Cognitive Psychology, 41, 49-100.

Morrison, A. B., \& Chein, J. M. (2011). Does working memory training work? The promise and challenges of enhancing cognition by training working memory. Psychonomic Bulletin \& Review, 18, 46-60.

Nederkoorn, C., Houben, K., Hofmann, W., Roefs, A., \& Jansen, A. (2010). Control yourself or just eat what you like?. Weight gain over a year is predicted by an interactive effect of response inhibition and a preference for high fat foods. Health Psychology, 29, 389-393. 
Olshansky, S. J., Passaro, D. J., Hershow, R. C., Layden, J., Carnes, B. A., Brody, J., ... Ludwig, D. S. (2005). A potential decline in life expectancy in the United States in the 21st century. The New England Journal of Medicine, 352, 1138-1145.

Schmeichel, B. J., \& Demaree, H. A. (2010). Working Memory Capacity and Spontaneous Emotion Regulation: High Capacity Predicts Self-Enhancement in Response to Negative Feedback. Emotion, 10 , 739-744.

Schmeichel, B. J., Volokhov, R. N., \& Demaree, H. A. (2008). Working memory capacity and the self-regulation of emotional expression and experience. Journal of Personality and Social Psychology, 95, 1526-1540.

Shipstead, Z., Redick, T. S., \& Engle, R. W. (2012). Is working memory training effective? Psychological Bulletin, 138, 628-654.

Smith, E., Hay, P., Campbell, L., \& Trollor, J. N. (2011). A review of the association between obesity and cognitive function across the lifespan: implications for novel approaches to prevention and treatment. Obesity Reviews, 12, 740-755.

Strack, F., \& Deutsch, R. (2008). Reflective and impulsive determinants of social behavior. Personality and Social Psychology Review, 8, 220-247.

Van Strien, T. (2005). Nederlandse vragenlijst voor eetgedrag [Dutch Eating Behaviour Questionnaire, manual]. Amsterdam: Boom Test Publishers

Van Strien, T., Frijters, J. E., Bergers, G. P. A., \& Defares, P. B. (1986). The Dutch Eating Behaviour Questionnaire (DEBQ) for assessment of restrained, emotional and external eating behaviour. International Journal of Eating Disorders, 5, 295-315.

Veling, H., Aarts, H., \& Papies, E. K. (2011). Using stop signals to inhibit chronic dieters' responses toward palatable foods. Behaviour Research and Therapy, 49, 771-780. 
619 Veling, H., Aarts, H., \& Stroebe, W. (2013). Using stop signals to reduce impulsive

620 choices for palatable unhealthy foods. British Journal of Health Psychology, 18, $621 \quad 354-368$.

622 Veling, H., van Koningsbruggen, G. M., Aarts, H., \& Stroebe, W. (2014). Targeting 623 impulsive processes of eating behavior via the internet. Effects on body weight.

624 Appetite, 78, 102-109.

625 Vreugdenburg, L., Bryan, J., \& Kemps, E. (2003). The effect of self-initiated weight-loss 626 dieting on working memory: The role of preoccupying cognitions. Appetite, 41 , $627 \quad 291-300$.

628 Wang, Y., \& Beydoun, M. A. (2007). The obesity epidemic in the United States629 gender, age, socioeconomic, racial/ethnic, and geographic characteristics: a 630 systematic review and meta-regression analysis. Epidemiologic Reviews, 29, 6-28. 631 World Health Organization (WHO) (2009). Global health risks: mortality and burden of 632 disease attributable to selected major risks. Geneva, Switzerland: World Health 633 Organization. 
Table1 Participant characteristics per training condition. M eans and standard deviations for baseline characteristics are provided per condition

\begin{tabular}{llllll}
\hline & Training $(\mathrm{N}=24)$ & Control $(\mathrm{N}=26)$ & Range & $\mathrm{F} / \chi^{2}$ & $\mathrm{p}$ \\
\hline Age & $36.08(11.28)$ & $37.62(10.65)$ & $18-62$ & .24 & .62 \\
Baseline BMI (kg/ $\left.\mathrm{m}^{2}\right)$ & $31.76(3.79)$ & $31.38(3.72)$ & $26.50-41.58$ & .13 & .72 \\
Gender (\% female) & $79.2 \%$ & $69.2 \%$ & - & .64 & .42 \\
Dietary restraint (RS) & $17.50(3.71)$ & $16.69(5.19)$ & $3-27$ & .40 & .53 \\
Working Memory & $6.15(1.54)$ & $6.06(1.32)$ & $3.00-9.67$ & .05 & .83 \\
(WM ) - baseline & & & & & \\
\hline
\end{tabular}


Table2 $\mathrm{M}$ eans and standard deviations for the dependent measures at pretest, posttest and one-month follow-up, per condition

\begin{tabular}{|c|c|c|c|c|c|c|}
\hline & \multicolumn{3}{|c|}{ Training $(\mathrm{N}=24)$} & \multicolumn{3}{|c|}{ Control $(\mathrm{N}=26)$} \\
\hline DEBQ external eating & $3.07(.54)$ & $2.97(.51)$ & $2.87(.59)$ & $3.10(.63)$ & $2.94(.51)$ & $2.91(.64)$ \\
\hline EDE-Q eating concern & $1.10(.89)$ & $.57(.56)^{*}$ & $.74(.75)^{*}$ & $.96(.82)$ & $.84(.78)$ & $.79(.65)$ \\
\hline EDE-Q shape concern & $3.04(1.52)$ & $2.14(1.28)^{*}$ & $2.23(1.39)^{*}$ & $2.31(1.33)$ & $2.18(1.30)$ & $2.14(1.44)$ \\
\hline EDE-Q weight concern & $2.65(1.37)$ & $2.10(1.26)$ & $2.02(1.38)$ & $2.22(1.42)$ & $2.07(1.31)$ & $2.08(1.42)$ \\
\hline Food intake (kcal) & $243.72(203.60)$ & $309.67(289.46)$ & $296.83(233.39)$ & $266.83(138.19)$ & 299.37 (174.61) & $345.40(348.40)$ \\
\hline $\mathrm{BM} I\left(\mathrm{~kg} / \mathrm{m}^{2}\right)$ & $31.76(3.79)$ & $31.62(3.76)$ & $31.63(3.84)$ & $31.38(3.72)$ & $31.31(3.94)$ & $31.25(3.96)$ \\
\hline
\end{tabular}

Note ${ }^{*}=$ Significantly different from pretest at $p<.05$. 
Figure 1 The number of items that could be correctly recalled in a WM sequence at the end of each training/control session, averaged across the three training tasks (working memory span), separately for the training condition and the control condition.

Figure $2 \mathrm{M}$ eans and standard errors for WM performance at pretest, posttest and one-month follow-up, per condition.

Note: * indicates significant differences at $p<.05$

Figure 3 Estimated marginal means (with standard errors) for caloric intake at pretest, posttest and one-month follow-up, per condition. Means are shown separately for low restrained versus highly restrained eaters (respectively 1 SD below or above the mean restraint score).

Note: * indicates significant differences at $p<.05$ 